\title{
High-dose cannabidiol induced hypotension after global hypoxia-ischemia in piglets.
}

Running title: $\mathrm{CBD}$ after neonatal hypoxia-ischemia

Keywords: newborn piglet, cannabidiol, side-effects, neuroprotection, neonatal hypoxia-ischemia, hypoxic-ischemic brain injury, neonatal haemodynamics, hypotension,

\section{Authors:}

Håvard T. Garberg ${ }^{1,2}$, Rønnaug Solberg ${ }^{1}$, Jon Barlinn ${ }^{1}$, Jose Martinez-Orgado ${ }^{4}$, ElseMarit Løberg ${ }^{2,3}$ and Ola Didrik Saugstad ${ }^{1,2}$.

\section{Affiliations:}

${ }^{1}$ Department of Pediatric Research, Division of Pediatric and Adolescent medicine, Oslo University Hospital, Rikshospitalet, Oslo, Norway

${ }^{2}$ University of Oslo, Oslo, Norway

${ }^{3}$ Department of Pathology, Oslo University Hospital, Ullevål, Oslo, Norway

${ }^{4}$ Division of Neonatology, Hospital Clinico San Carlos-IdISSC, Madrid, Spain

* Corresponding author: Håvard T. Garberg, Department of Pediatric Research, Oslo University Hospital, PB 4950 Nydalen, 0424 Oslo, Norway.

E-mail: hgarberg@gmail.com, haagar@research-rr.no. Phone: +4748273132

Financial support: GW pharmaceuticals (GW Research Ltd, Cambridge, UK) covered the costs of piglets included in this study and provided the study drug.

Disclosure statement: GW pharmaceuticals had the chance to read and comment on the manuscript, but the final version solely represents the author`s views.

The manuscript is not under consideration for publication elsewhere. 


\section{Abstract}

Background: Cannabidiol (CBD) is considered a promising neuroprotectant in the setting of perinatal hypoxia-ischemia (HI). We have previously studied the effects of CBD $1 \mathrm{mg} / \mathrm{kg}$ in the early phase after global $\mathrm{HI}$ in piglets. In contrast to existing studies found no evidence of neuroprotection and hypothesized that higher doses might be required to demonstrate efficacy in this animal model.

Objective: To assess the safety and possible neuroprotective effects of high-dose CBD. Methods: Anesthetized newborn piglets underwent global $\mathrm{HI}$ by ventilation with $8 \% \mathrm{O} 2$ until the point of severe metabolic acidosis ( $\mathrm{BE}-20 \mathrm{mmol} / \mathrm{l}$ ) and/or hypotension (MABP $\leq 20$ $\mathrm{mmHg})$. Piglets were randomized to intravenous treatment with vehicle $(n=9)$ or CBD $(n=13)$. The starting dose of CBD $50 \mathrm{mg} / \mathrm{kg}$ was reduced if adverse effects occurred. Piglets were euthanized 9.5 hours after $\mathrm{HI}$ and tissue was collected for analysis.

Results: CBD $50 \mathrm{mg} / \mathrm{kg}(\mathrm{n}=4)$ induced significant hypotension in 2 out of 4 piglets and 1 out of 4 piglets suffered fatal cardiac arrest. CBD $25 \mathrm{mg} / \mathrm{kg}(\mathrm{n}=4)$ induced significant hypotension in 1 out of 4 piglets, while $10 \mathrm{mg} / \mathrm{kg}(\mathrm{n}=5)$ was well tolerated. A significant negative correlation between the plasma concentration of $\mathrm{CBD}$ and hypotension during drug infusion was observed $(p<0.005)$. Neuroprotective effects were evaluated in piglets that did not display significant hypotension $(n=9)$ and $C B D$ did not alter the degree of neuronal damage as measured by neuropathology score, the levels of the astrocytic marker S100B in CSF, magnetic resonance spectroscopy markers (Lac/NAA \& Glu/NAA ratios) or troponin-T in plasma.

Conclusions: High-dose CBD induced severe hypotension and did not offer neuroprotection in the early phase after global $\mathrm{HI}$ in piglets. 


\section{Introduction}

Cannabidiol (CBD), a non-psychotropic cannabinoid, has over the last decade emerged as a promising neuroprotectant for the treatment of neonatal hypoxicischemic encephalopathy [1-6] and has received orphan designation status for this condition [7].

Neuroprotection by CBD after perinatal hypoxia-ischemia ( $\mathrm{HI})$ has been demonstrated after doses ranging from $0.1-1000 \mu \mathrm{M}$ in whole brain-slices from mice [8], 1-30 mg/kg intraperitoneally in rats [9] and 0.1-1 mg/kg intravenously (i.v) in piglets [3-5]. We recently studied the effects of CBD $1 \mathrm{mg} / \mathrm{kg}$ i.v in a piglet model of global hypoxia-ischemia (HI) [10] and in contrast to previous studies in piglets [2-5] no neuroprotective effects were found early phase after HI. The hypoxic-ischemic insult in our model produces a more severe multi-organ damage compared to these studies [2-5]. As the effects of cannabinoids have been shown to depend both on the dose and pathophysiological setting $[11,12]$ we hypothesized that higher doses of CBD could be required to demonstrate efficacy in this animal model.

However, when considering high-dose CBD in this setting it is important to be aware of its possible effects on other organs. Like the cardiovascular system where CBD`s actions on the heart and vasculature have been demonstrated in several in-vitro studies [12-15]. Even though intravenous CBD up to $100 \mathrm{mg} / \mathrm{kg}$ in animal models [16] and $30 \mathrm{mg} / \mathrm{kg}$ in humans $[16,17]$ have been well tolerated, these studies did not 
involve global $\mathrm{HI}$ which is known to induce cardiovascular dysfunction [18]. In piglets exposed to $\mathrm{HI}$ the highest dose of CBD yet to be tested is $1 \mathrm{mg} / \mathrm{kg}$ i.v and it did not produce unwanted cardiovascular effects $[3,4,10]$.

Hence the aim of this study was to evaluate the safety of high-dose CBD (>10 mg/kg) after global $\mathrm{HI}$ in piglets, and further to perform a preliminary assessment of possible neuroprotective effects.

\section{Materials and methods}

\section{Approval}

The Norwegian Council for Animal Research approved the experimental protocol (approval number 7359). The animals were cared for and handled in accordance with the European Guidelines for Use of Experimental Animals, by certified FELASA (Federation of European Laboratory Animals Science Associations) Category C researchers.

\section{Experimental protocol}

The animal model used have been extensively described previously [10]. Briefly; 22 newborn Noroc (LyxLD) pigs were exposed to hypoxia-ischemia (HI) by ventilation with a gas mixture of $8 \% \mathrm{O}_{2}$ in $\mathrm{N}_{2}$ until either the mean arterial blood pressure (MABP) decreased to $20 \mathrm{mmHg}$ or the base excess $(\mathrm{BE})$ reached $-20 \mathrm{mmol} / \mathrm{L}$. After resuscitation piglets were randomized, by sealed envelopes, to treatment with high- 
dose CBD ( $n=13)$ or Vehicle (VEH) ( $n=9)$. We have previously demonstrated a significant effect of $\mathrm{HI}$ on the parameters assessed in this study [10] and thus a nonhypoxic control group was not included in the current experiments.

The MABP was measured continuously in the left carotid artery using BioPac systems MP150-CE (Goleta, USA). The O2 saturation was monitored by pulsoxymetry (Masimo RAD-5 pulsoxymeter, Neuchatel, Switzerland). Rectal temperature was measured by digital rectal thermometer and maintained between 38.5 and $40.0^{\circ} \mathrm{C}$. Temperature-corrected arterial acid/base status, glucose and hemoglobin were regularly measured on a Blood Gas Analyzer 860 (Ciba Corning Diagnostics, Midfield, Mass., USA). Apart from during the hypoxic insult mechanical ventilation settings were adjusted to maintain normoventilation.

Blood and CSF for analysis were obtained at the end of the experiment ( 9.5 hours after $\mathrm{HI}$ ). Samples were immediately snap-frozen in liquid nitrogen and stored at minus $80^{\circ} \mathrm{C}$. The animals were euthanized with an overdose of pentobarbital (150 $\left.\mathrm{mg} \mathrm{kg}^{-1} \mathrm{IV}\right)$. The brain was immediately removed and sagitally divided. From the right half, specimens from the fronto-parietal cortex and the hippocampus were snapfrozen in liquid nitrogen and stored at $-80^{\circ} \mathrm{C}$ until subsequent analysis. The left hemisphere was placed in $4 \%$ buffered formalin for subsequent histopathological analysis.

\section{Dose and administration of cannabidiol}

A starting dose of CBD $50 \mathrm{mg} / \mathrm{kg}$ (GW Research Ltd, Cambridge, UK) was chosen based on existing literature [16]. If significant side effects occurred the dose was to 
be reduced step-wise to $25 \mathrm{mg} / \mathrm{kg}, 10 \mathrm{mg} / \mathrm{kg}$ and further to $5 \mathrm{mg} / \mathrm{kg}$. Side effects evaluated were severe hypotension, defined as drop in blood pressure to $<70 \%$ of baseline MABP (start infusion).

CBD was prepared in a $10 \mathrm{mg} / \mathrm{ml}$ formulation of ethanol:solutol:saline at a ratio of 2:1:17. CBD was mixed with saline to give a total volume of $20 \mathrm{ml}$. Vehicle treated animals received an equivalent amount of vehicle to the CBD $50 \mathrm{mg} / \mathrm{kg}$ dose regimen. CBD and vehicle were given 30 minutes after the end of hypoxia i.v over 15 minutes.

\section{Plasma and brain concentrations CBD}

Plasma and brain levels of CBD were determined by liquid chromatography-tandem mass spectrometry (LC-MS/MS) at LGC (Fordham, UK).

\section{Histology}

A transcoronal block ( 0,4 $\mathrm{cm}$ thick) from the level of parietal cortex including basal ganglia was prepared, processed in a Leica TP1050 tissue processor (GMI, Minnesota, 55303, USA), embedded in paraffin, sliced in 4- $\mu$ m-thick sections and stained with hematoxylin and eosin (H\&E).

Analysis was performed by an experienced pathologist blinded to the randomization/clinical details. Areas with vacuolated neuropil, shrunken neurons with pyknotic nuclei and scattered eosinophilic neurons were defined as early neuronal damage. A modified version of a validated scoring system [19] was used. Based on evaluation of the whole brain section, including cortex, white matter and 
basal ganglia, a global score with 8 levels, ranging from 0-4, was given to each piglet. Zero representing no damage, 0.5 - 1.5: mild/moderate, 2-2.5: moderate/severe, 33.5: severe and 4: massive damage with autolysis of the brain.

\section{Biomarkers}

S100B in CSF and plasma Troponin-T were measured using electrochemiluminescent immunometric assay (ECLIA) on the Cobas e601 immunoassay platform (Roche D, Mannheim, Germany).

\section{Proton-magnetic-resonance-spectroscopy (H+-MRS)}

$\mathrm{H}^{+}$-MRS was performed by the collaborative unit in Madrid in the MRI Unit of the Instituto Pluridisciplinar (Universidad Complutense, Madrid, Spain) and the method is extensively described in the papers by Pazos et al [4] and Lafuente et al [3].

\section{Statistical analysis}

Statistical analyses were performed by SPSS v.21 (Chicago, USA) and GraphPad Prism 6 (GraphPad Prism Software Inc, La Jolla, CA). Non-normally distributed data were log transformed and if unsuccessful non-parametric statistics was used. Comparison of cohort characteristics were analyzed by one-Way ANOVA with Dunn`s post-hoc test. Descriptive results are presented with means \pm standard deviations, standard error of mean or median with intra-quartile range as appropriate. High-dose CBD was compared to VEH by independent t-tests or Mann-whitney test. Correlations were calculated by Spearman rank correlation coefficient. A 5\% significance level was used. 


\section{Results}

\section{Cohort description}

Twenty-two piglets were included in the study (VEH=9 and $C B D=13)$. No significant differences in baseline physical variables or biophysical and biochemical variables were observed between the study groups (table 1)

\section{Plasma and brain concentrations}

The plasma and brain concentrations of CBD showed a linear relationship with the dose (figure 1). CBD levels in the brain were strongly correlated with plasma levels ( $\beta$ $=0.4 \mu \mathrm{g}, 95 \% \mathrm{Cl}[0.3$ to 0.5$], \mathrm{p}<0.0001$ ) (fig $1 \mathrm{c}$ ).

\section{Safety}

There were no significant group differences in hemodynamic variables before treatment (table 1). No significant difference in heart rate was observed during treatment (table 1). 3/4 piglets in the CBD $50 \mathrm{mg} / \mathrm{kg}$ group displayed significant hypotension, with a drop in MABP below $70 \%$ of baseline. One of these piglets suffered a fatal cardiac arrest immediately after the end of infusion. The mean drop was significant compared to VEH (CBD - $26 \pm 9 \mathrm{mmHg}$ vs. VEH - $2 \pm 4 \mathrm{mmHg}$, p<0.0001) (fig $2 \& 3 a$ ). 1/4 piglets receiving $25 \mathrm{mg} / \mathrm{kg}$ displayed severe hypotension, but group mean drop was not significant (CBD $25 \mathrm{mg} / \mathrm{kg}-8 \pm 10 \mathrm{mmHg}$ vs. VEH $-2 \pm 4$ $\mathrm{mmHg}, \mathrm{p}=0.29)$. VEH and CBD $10 \mathrm{mg} / \mathrm{kg}$ did not produce significant hypotension. We observed a significant negative association between the plasma concentration of 
$\mathrm{CBD}$ at 3 hours post-dose and MABP with a mean drop of $-1 \mathrm{mmHg}(95 \% \mathrm{Cl}[-1.7$ to 0.5], $p=0.002$ ) per $1 \mu \mathrm{g}$ increase in CBD (fig 3b)).

\section{Neuroprotection}

The neuropathology score was not significantly different in piglets receiving highdose CBD compared to VEH (CBD score $1.9 \pm 1.4$ vs. VEH $1.6 \pm 1.3, p=0.67$ ) and CBD did not significantly alter the levels of S100B in cerebrospinal fluid (CBD $17.8 \pm 11.9$ $\mathrm{ng} / \mathrm{ml}$ vs. VEH $11.5 \pm 11.9 \mathrm{ng} / \mathrm{ml}, \mathrm{p}=0.3$ ). High-dose CBD did not mitigate the increase in Lac/NAA ratio (CBD 3.8 (3.4- 9.9) vs. VEH 3.7 (3.3-4.9), $p=0.55$ ) or Glu/NAA ratio (CBD $1.4 \pm 0.3$ vs. VEH $1.3 \pm 0.2, p=0.44$ ). Levels of plasma troponin- $-\mathrm{T}$ were not significantly different in piglets who received high-dose CBD compared to VEH (CBD $155 \pm 179 \mathrm{ng} / \mathrm{L}$ vs. VEH $240 \pm 230 \mathrm{ng} / \mathrm{L}, \mathrm{p}=0.42$ ) (results summarized in table 2).

The above analysis included all animals receiving high-dose CBD $(n=9)$ with vehicle $(n=9)$, excluding piglets who displayed severe hypotension during treatment $(n=4)$. Sub-group analysis of the individual doses of CBD had, prior to this, not shown significant differences among groups.

\section{Discussion}

In this study we have evaluated the safety of high dose CBD in newborn piglets exposed to global $\mathrm{HI}$ as well as performed a preliminary assessment of efficacy. We 
have demonstrated that high-dose CBD in this setting can induce severe hypotension in some animals. Further, high-dose CBD did not offer neuroprotection in the first 9.5 hours after $\mathrm{HI}$ as evaluated by a neuropathology score, levels of the astrocytic marker S100B in cerebrospinal fluid, hippocampal proton magnetic resonance spectroscopy biomarkers or plasma troponin-T levels.

CBD has been shown to induce hypotension in animals previously [12], but in most studies even high doses has been well tolerated [16]. However, these models did not induce severe global HI. Cardiovascular dysfunction in the current animal model is demonstrated by severe hypotension during hypoxia-ischemia and in the recovery phase; a degree of persistent hypotension and tachycardia as well as significantly elevated plasma troponin-T [10]. High-dose CBD did not induce cardiac arrhythmias or significant alterations in heart rate. Still, in this setting of a compromised myocardial function [18] , CBD`s vasorelaxant effects $[14,20]$, it ability to depress the contractility of myocytes[15], and to reduce the cardiovascular response to stress [13] can all be potential explanations for the observed hypotension.

A significant correlation between the plasma concentrations of CBD and the degree of hypotension during infusion was observed. All piglets with a significant drop in MABP had plasma levels of CBD above 4 micrograms $/ \mathrm{ml}$ at 3 hours post dose. This corresponds to an estimated molar concentration of approximately $13 \mu \mathrm{M}$. The initial concentrations, however, are likely far greater as Cmax after intravenous 
administration is achieved almost instantaneously. In an in-vitro study on the preconstricted rat aorta, CBD 5 to $10 \mu \mathrm{M}$ were found to induce a $25-50 \%$ relaxation respectively [20] and in another in-vitro study on rat myocytes, CBD as low as $1 \mu \mathrm{M}$ were found to exert negative inotropic effects [15]. We should, however be cautious when extrapolating the effects of in-vitro concentrations to in-vivo studies [21] as well as across species. Modifications in the method of CBD administration, e.g. by using a slower infusion rate or giving CBD later when cardiovascular function has improved, could have limited the observed effects. Further, we did not treat hypotension with vasopressors or inotropic drugs. Nonetheless, the possibility of inducing unwanted hypotension is a possible limitation of the highest doses of CBD in this setting.

We found no significant protective effects of high-dose CBD on the levels of early neuronal damage assessed by neuropathology. Nor did CBD alter the levels of S100B in cerebrospinal fluid or plasma troponin-T, both of which have been found to predict outcome after perinatal HI $[18,22]$. Proton magnetic spectroscopy biomarkers, especially the Lac/NAA ratio are early predictors of outcome after neonatal $\mathrm{HI}$ [23], but were not influenced by high-dose CBD in our study. Although we have evaluated a limited number of variables, they have all been used previously to demonstrate CBD`s neuroprotective effects in piglets [3-5]. Explanations for the lack of effects in our model compared to previous studies in piglets [2-5] have been thoroughly discussed before [10]. Most relevant is probably the difference in the 
nature of $\mathrm{HI}$. Among others, the duration of $\mathrm{HI}$ is longer in our model (40-55 vs. $20-$ 30 minutes) and piglets have a more profound metabolic acidosis ( $\mathrm{pH} 6.85$ vs. 7.2).

In regard to neuroprotection; an important limitation of this study is the early endpoint used for analysis as it allows us only to study effects limited to the latent phase and early secondary energy failure after perinatal HI [24]. Nevertheless the majority of the existing literature in support of CBD`s neuroprotective effects after neonatal $\mathrm{HI}$, have used comparable end-points (6 hours) [2-4] . As such the evidence of CBD`s full potential after perinatal $\mathrm{HI}$ is still limited and difficult to interpret. Further, we acknowledge the relatively small sample size and the variation in degree of injury after $\mathrm{HI}$ seen in this model. The animals excluded due to severe hypotension did not display significant differences in the outcome variables related to neuroprotection and including them would not have altered the overall results. Nevertheless, we found it most appropriate to exclude them based on the probability of brain ischemia caused by such a severe drop in MABP, which is considered to be below the lower limit of cerebral auto-regulation in piglets [25].

Before considering clinical trials with $\mathrm{CBD}$ in the setting of perinatal $\mathrm{HI}$ it is important to confirm its safety and efficacy in different preclinical models and in our opinion this study has relevance in this regard. Although adverse effects were seen only after the highest doses, and might be prevented by modifications in the timing and method of administration, they are important to consider in future studies. In the 
current animal model CBD has failed to demonstrate neuroprotective effects, yet its full neuroprotective potential and optimal dose remains to be determined.

\section{Acknowledgements:}

We thank Corina Silvia Rueegg at the department of Biostatistics, University of Oslo for statistical advice, Ingeborg Løstegaard Goverud at the department of Pathology, Oslo University Hospital for assistance with histopathology and the Department of Medical Biochemistry, Oslo University Hospital, for analysis of S100B and troponin-T. 


\section{References:}

1 England TJ, Hind WH, Rasid NA, O'Sullivan SE: Cannabinoids in experimental stroke: a systematic review and meta-analysis. J Cereb Blood Flow Metab 2015;35:348-358.

2 Alvarez FJ, Lafuente H, Rey-Santano MC, Mielgo VE, Gastiasoro E, Rueda M, Pertwee RG, Castillo AI, Romero J, Martínez-Orgado J: Neuroprotective effects of the nonpsychoactive cannabinoid cannabidiol in hypoxic-ischemic newborn piglets. Pediatr Res 2008;64:653-658.

3 Lafuente H, Pazos MR, Alvarez A, Mohammed N, Santos M, Arizti M, Alvarez FJ, MartinezOrgado JA: Effects of Cannabidiol and Hypothermia on Short-Term Brain Damage in New-Born Piglets after Acute Hypoxia-Ischemia. Front Neurosci 2016;10:323.

4 Pazos MR, Mohammed N, Lafuente H, Santos M, Martinez-Pinilla E, Moreno E, Valdizan E, Romero J, Pazos A, Franco R, Hillard CJ, Alvarez FJ, Martinez-Orgado J: Mechanisms of cannabidiol neuroprotection in hypoxic-ischemic newborn pigs: role of 5HT(1)A and CB2 receptors.

Neuropharmacology 2013;71:282-291.

5 Lafuente H, Alvarez FJ, Pazos MR, Alvarez A, Rey-Santano MC, Mielgo V, Murgia-Esteve

$\mathrm{X}$, Hilario E, Martinez-Orgado J: Cannabidiol reduces brain damage and improves functional recovery after acute hypoxia-ischemia in newborn pigs. Pediatr Res 2011;70:272-277.

6 Campos AC, Fogaca MV, Sonego AB, Guimaraes FS: Cannabidiol, neuroprotection and neuropsychiatric disorders. Pharmacol Res 2016

$7 \quad$ Administration USFaD:

http://www.accessdata.fda.gov/scripts/opdlisting/oopd/OOPD Results 2.cfm,

$8 \quad$ Castillo A, Tolón MR, Fernández-Ruiz J, Romero J, Martinez-Orgado J: The neuroprotective effect of cannabidiol in an in vitro model of newborn hypoxic-ischemic brain damage in mice is mediated by CB(2) and adenosine receptors. Neurobiol Dis 2010;37:434-440.

9 Pazos MR, Cinquina V, Gómez A, Layunta R, Santos M, Fernández-Ruiz J, Martínez-Orgado J: Cannabidiol administration after hypoxia-ischemia to newborn rats reduces long-term brain injury and restores neurobehavioral function. Neuropharmacology 2012;63:776-783.

10 Garberg HT, Huun MU, Escobar J, Martinez-Orgado J, Loberg EM, Solberg R, Saugstad OD: Short-term effects of cannabidiol after global hypoxia-ischemia in newborn piglets. Pediatr Res 2016

11 Sarne Y, Asaf F, Fishbein M, Gafni M, Keren O: The dual neuroprotective-neurotoxic profile of cannabinoid drugs. Br J Pharmacol 2011;163:1391-1401.

12 Walsh SK, Hepburn CY, Keown O, Astrand A, Lindblom A, Ryberg E, Hjorth S, Leslie SJ, Greasley PJ, Wainwright CL: Pharmacological profiling of the hemodynamic effects of cannabinoid ligands: a combined in vitro and in vivo approach. Pharmacol Res Perspect 2015;3:e0143.

13 Resstel LB, Tavares RF, Lisboa SF, Joca SR, Correa FM, Guimaraes FS: 5-HT1A receptors are involved in the cannabidiol-induced attenuation of behavioural and cardiovascular responses to acute restraint stress in rats. Br J Pharmacol 2009;156:181-188.

14 Stanley CP, Hind WH, Tufarelli C, O'Sullivan SE: Cannabidiol causes endotheliumdependent vasorelaxation of human mesenteric arteries via CB1 activation. Cardiovasc Res 2015;107:568-578.

15 Ali RM, Al Kury LT, Yang KH, Qureshi A, Rajesh M, Galadari S, Shuba YM, Howarth FC, Oz M: Effects of cannabidiol on contractions and calcium signaling in rat ventricular myocytes. Cell Calcium 2015;57:290-299.

16 Bergamaschi MM, Queiroz RH, Zuardi AW, Crippa JA: Safety and side effects of cannabidiol, a Cannabis sativa constituent. Curr Drug Saf 2011;6:237-249.

17 Hill AJ, Williams CM, Whalley BJ, Stephens GJ: Phytocannabinoids as novel therapeutic agents in CNS disorders. Pharmacol Ther 2012;133:79-97.

18 Armstrong K, Franklin O, Sweetman D, Molloy EJ: Cardiovascular dysfunction in infants with neonatal encephalopathy. Arch Dis Child 2012;97:372-375.

19 Haaland K, Løberg EM, Steen PA, Thoresen M: Posthypoxic hypothermia in newborn piglets. Pediatr Res 1997;41:505-512.

20 O'Sullivan SE, Sun Y, Bennett AJ, Randall MD, Kendall DA: Time-dependent vascular actions of cannabidiol in the rat aorta. European Journal of Pharmacology 2009;612:61-68.

21 Ibeas Bih C, Chen T, Nunn AV, Bazelot M, Dallas M, Whalley BJ: Molecular Targets of Cannabidiol in Neurological Disorders. Neurotherapeutics 2015;12:699-730.

22 Massaro AN, Chang T, Baumgart S, McCarter R, Nelson KB, Glass P: Biomarkers S100B and neuron-specific enolase predict outcome in hypothermia-treated encephalopathic newborns*. Pediatr Crit Care Med 2014;15:615-622. 

Omar RZ, Robertson NJ: Cerebral magnetic resonance biomarkers in neonatal encephalopathy: a metaanalysis. Pediatrics 2010;125:e382-395.

24 Wassink G, Gunn ER, Drury PP, Bennet L, Gunn AJ: The mechanisms and treatment of asphyxial encephalopathy. Frontiers in Neuroscience 2014;8:40.

25 Lee JK, Brady KM, Mytar JO, Kibler KK, Carter EL, Hirsch KG, Hogue CW, Easley RB, Jordan LC, Smielewski P, Czosnyka M, Shaffner DH, Koehler RC: Cerebral Blood Flow and Cerebrovascular Autoregulation in a Swine Model of Pediatric Cardiac Arrest and Hypothermia. Critical care medicine 2011;39:2337-2345. 
Tables

\begin{tabular}{|c|c|c|c|c|c|c|c|c|c|}
\hline & $\begin{array}{l}\text { Vehic } \\
(n=9)\end{array}$ & & $\begin{array}{l}\text { CBD } \\
10 \mathrm{mg} \\
(\mathrm{n}=5)\end{array}$ & & $\begin{array}{l}\text { CBD } \\
25 \mathrm{~m} \\
(\mathrm{n}=4)\end{array}$ & & $\begin{array}{l}\text { CBD } \\
50 \mathrm{mg} \\
(\mathrm{n}=4)\end{array}$ & & \\
\hline & Mean & SD & Mean & SD & Mean & SD & Mean & SD & $P$ \\
\hline Weight (grams) & 2008 & 86 & 1900 & 121 & 1953 & 115 & 2069 & 90 & ns \\
\hline Age (hours) & 28 & 1 & 26 & 2.9 & 29 & 4 & 28 & 2 & ns \\
\hline $\mathrm{Hb}$ (g/dl) & 6.6 & 0.8 & 6.4 & 1.0 & 7.1 & 0.7 & 6.6 & 2.0 & ns \\
\hline Hypoxia (min) & 62 & 30 & 57 & 20 & 54 & 28 & 59 & 23 & ns \\
\hline $\mathrm{Tp}\left(\mathrm{C}^{0}\right)$ & & & & & & & & & \\
\hline S & 39.1 & 0.5 & 38.5 & 1.3 & 38.5 & 0.8 & 39.5 & 0.7 & ns \\
\hline E & 38.2 & 0.6 & 38.7 & 0.6 & 37.9 & 0.5 & 38.3 & 0.5 & ns \\
\hline $\mathbf{T}$ & 38.7 & 0.6 & 38.4 & 0.7 & 38.0 & 1.0 & 38.4 & 0.8 & ns \\
\hline 180 & 39.0 & 0.9 & 38.9 & 0.6 & 38.8 & 0.3 & 38.5 & 0.6 & ns \\
\hline ES & 38.6 & 0.8 & 38.6 & 0.5 & 38.8 & 0.5 & 38.8 & 0.6 & ns \\
\hline MABP $(\mathrm{mmHg})$ & & & & & & & & & \\
\hline S & 60.0 & 7.3 & 57.0 & 9.7 & 57.0 & 4.5 & 60.0 & 2.5 & ns \\
\hline E & 33.0 & 16.7 & 27.0 & 7.9 & 32.0 & 12.5 & 32.0 & 9.9 & ns \\
\hline$T$ & 48.0 & 10.5 & 44.0 & 4.4 & 53.0 & 7.3 & 50.0 & 6.2 & ns \\
\hline HR (bpm) & & & & & & & & & \\
\hline$S$ & 154 & 12 & 156 & 21 & 130 & 27 & 141 & 31 & ns \\
\hline$E$ & 181 & 30 & 160 & 26 & 172 & 19 & 189 & 24 & ns \\
\hline $\mathbf{T}$ & 197 & 32 & 210 & 11 & 180 & 28 & 196 & 31 & ns \\
\hline ET & 196 & 31 & 222 & 19 & 187 & 22 & 166 & 58 & ns \\
\hline $\mathrm{pH}$ & & & & & & & & & \\
\hline$S$ & 7.4 & 0.1 & 7.4 & 0.1 & 7.4 & 0.1 & 7.4 & 0.1 & ns \\
\hline$E$ & 6.9 & 0.1 & 6.9 & 0.1 & 6.9 & 0.1 & 6.9 & 0.0 & ns \\
\hline 30 & 7.2 & 0.1 & 7.2 & 0.1 & 7.2 & 0.1 & 7.2 & 0.0 & ns \\
\hline 180 & 7.4 & 0.1 & 7.4 & 0.1 & 7.4 & 0.1 & 7.4 & 0.1 & ns \\
\hline ES & 7.4 & 0.1 & 7.4 & 0.0 & 7.4 & 0.0 & 7.4 & 0.0 & ns \\
\hline
\end{tabular}




\begin{tabular}{|c|c|c|c|c|c|c|c|c|c|}
\hline \multicolumn{10}{|c|}{ Lactate $(\mathrm{mmol} / \mathrm{l})$} \\
\hline $\mathbf{S}$ & 1.8 & 0.6 & 1.5 & 0.8 & 1.6 & 0.8 & 3.6 & 2.1 & ns \\
\hline $\mathbf{E}$ & 14.5 & 2.2 & 12.9 & 1.3 & 15.6 & 3.0 & 13.9 & 2.4 & ns \\
\hline $\mathbf{T}$ & 12.2 & 2.4 & 11.3 & 2.1 & 11.9 & 2.4 & 11.7 & 3.2 & ns \\
\hline 180 & 2.3 & 1.3 & 1.7 & 0.6 & 1.4 & 0.3 & 2.7 & 1.8 & ns \\
\hline ES & 1.5 & 1.4 & 1.1 & 0.3 & 1.0 & 0.3 & 0.8 & 0.2 & ns \\
\hline \multicolumn{10}{|l|}{ BE (mmol/l) } \\
\hline S & 3.0 & 3.1 & 1.7 & 1.7 & 1.9 & 1.6 & -1.0 & 2.7 & ns \\
\hline E & -18.1 & 3.0 & -18.7 & 2.2 & -18.1 & 2.4 & -18.6 & 0.9 & ns \\
\hline $\mathbf{T}$ & -13.0 & 1.7 & -13.6 & 2.5 & -12.5 & 3.7 & -13.1 & 1.6 & ns \\
\hline 180 & 1.1 & 2.1 & -0.2 & 1.4 & 2.8 & 2.8 & -1.3 & 1.3 & ns \\
\hline ES & -0.6 & 3.2 & -0.5 & 1.5 & 1.0 & 2.6 & 0.2 & 1.3 & ns \\
\hline
\end{tabular}

Table 1: Cohort description. Biophysical and biochemical variables at start $\mathrm{HI}$ (S), end $\mathrm{HI}(\mathrm{E})$, start of treatment (CBD/VEH) (T), end of treatment (ET), 180 min post treatment (180) and end of study, 540 min post treatment (ES).

$\mathrm{Hb}=$ hemoglobin, $\mathrm{Tp}=$ temperature, $\mathrm{MABP}=$ mean arterial blood pressure, $\mathrm{HR}=$ heart rate. $\mathrm{BE}=$ base excess $\mathrm{ns}=$ non significant. Statistics by one-way Anova with Dunnet's post hoc test. * One piglet in this group suffered fatal cardiac arrest immediately after CBD infusion and $\mathrm{n}$ is therefore 3 at 180 min post $\mathrm{HI}$ and at end-study. 


\begin{tabular}{|l|c|c|l|}
\hline & $\begin{array}{c}\text { Vehicle } \\
(\mathbf{n = 9})\end{array}$ & $\begin{array}{c}\text { High-dose CBD } \\
(\mathbf{n}=9)\end{array}$ & P-value \\
\hline Neuropathology score & $1.6(1.3)$ & $1.9(1.4)$ & 0.67 \\
\hline S100B ng/ml & $11.5(11.9)$ & $17.8(13.1)$ & 0.30 \\
\hline Lac/NAA ratio* & $3.7(3.3-4.9)$ & $3.8(3.4-9.9)$ & $0.55^{*}$ \\
\hline Glu/NAA ratio & $1.3(0.2)$ & $1.4(0.3)$ & 0.44 \\
\hline Troponin-T ng/L & $240(230)$ & $155(179)$ & 0.42 \\
\hline
\end{tabular}

Table 2: Neuroprotection. Comparison of the effects of high-dose CBD (excluding those with severe hypotension following infusion) vs. vehicle on the different outcome variables related to neuroprotection. Data are presented as mean (standard deviation) or median with intra-quartile range $\left({ }^{*}\right)$. Statistics was performed by independent t-test or Mann-Whitney test $\left(^{*}\right)$. 


\section{Figures}

a)

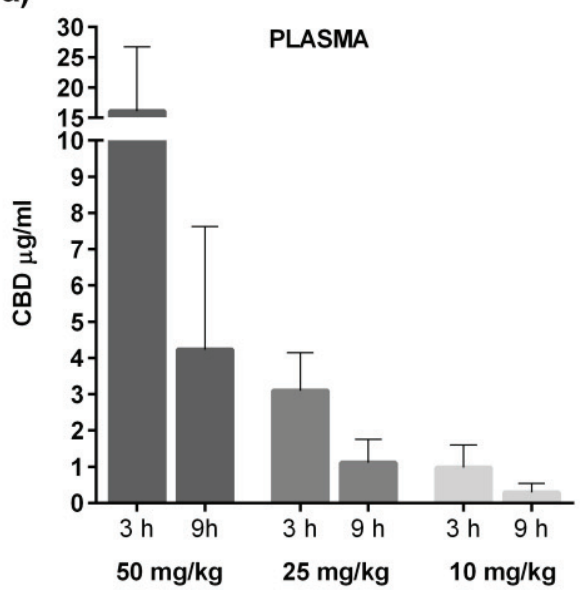

b)

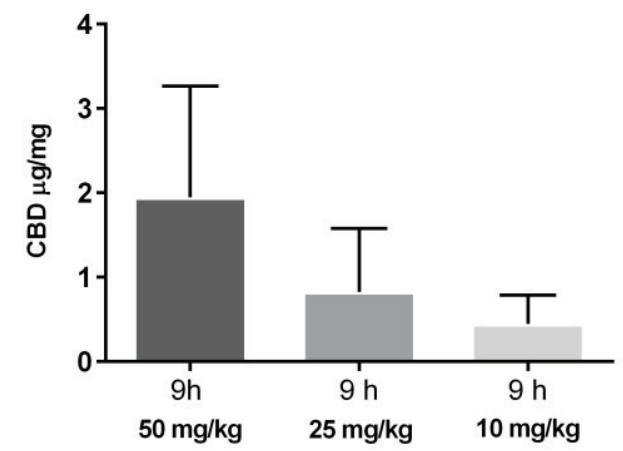

c)

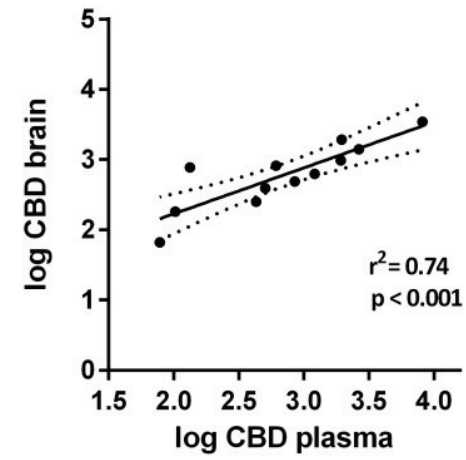

Fig 1: Plasma and brain concentration of CBD. Concentrations of CBD in plasma at 3 and 9 hours posttreatment (a) and brain 9 hours post-treatment (b). Correlation between plasma and brain levels at 9 hours post-treatment(c). Data are presented as mean \pm SD (a-b). 


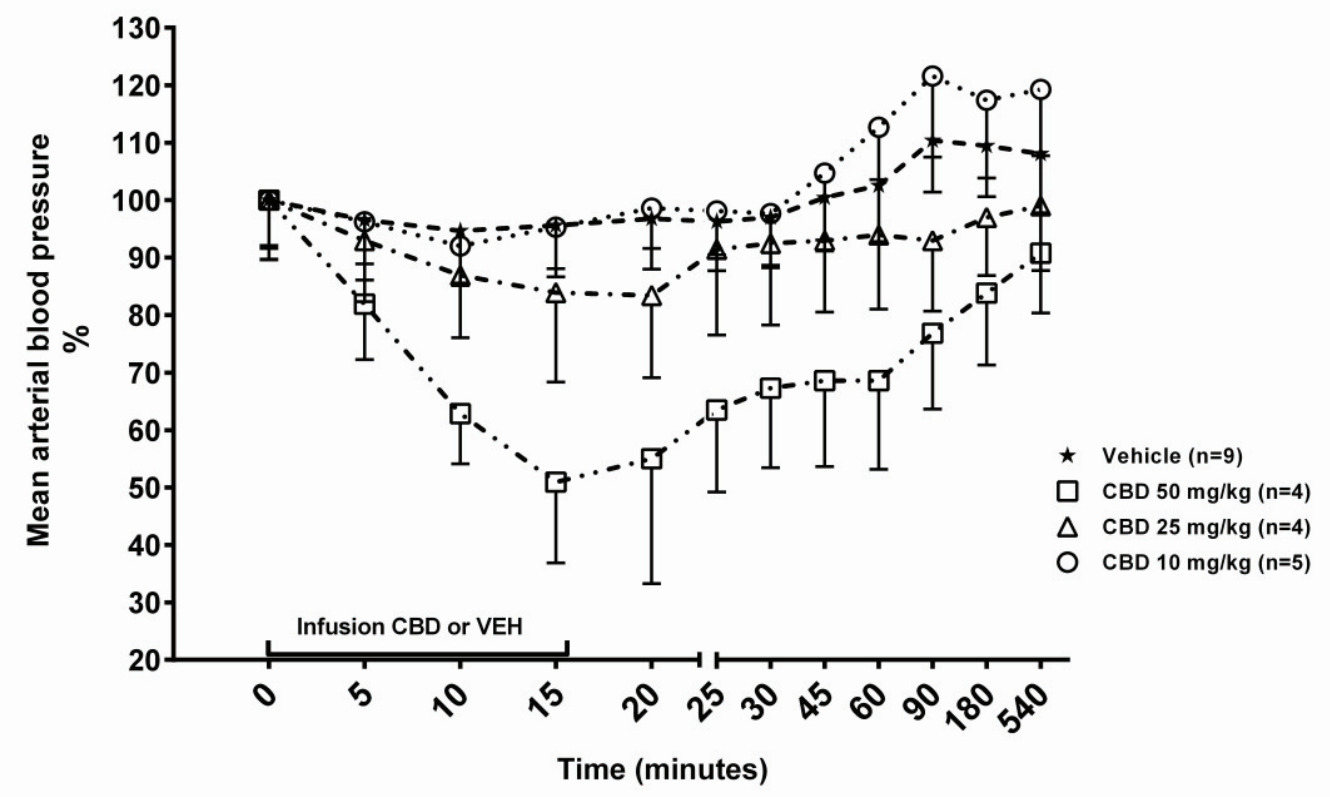

Fig 2. Blood pressure changes. Relative changes in mean arterial blood pressure (MABP) during infusion of CBD or VEH. Data presented as mean (-SEM) VEH: cross, CBD $50 \mathrm{mg} / \mathrm{kg}$ (squares) CBD 25 $\mathrm{mg} / \mathrm{kg}$ (triangles) CBD $10 \mathrm{mg} / \mathrm{kg}$ (circles). Note that one piglet receiving CBD $50 \mathrm{mg} / \mathrm{kg}$ suffered fatal cardiac arrest immediately after end of infusion and thus $n=3$ in this group from $20-540$ minutes. 
a)

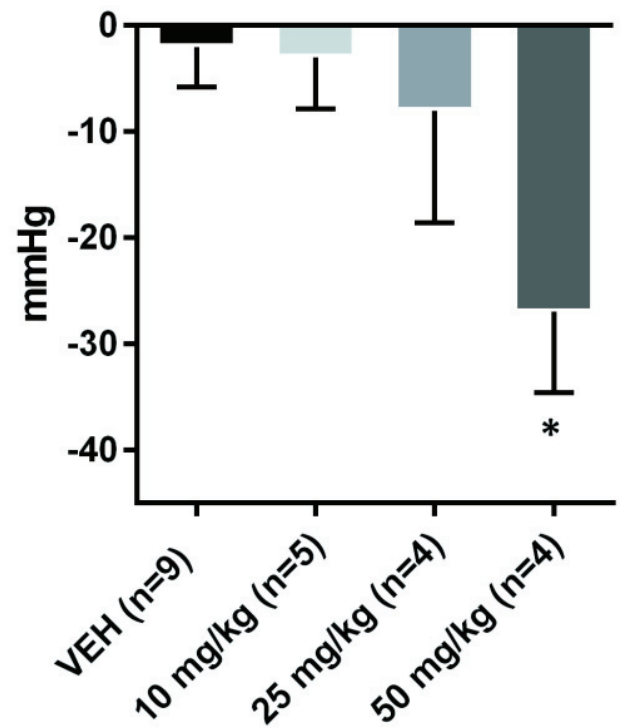

b)

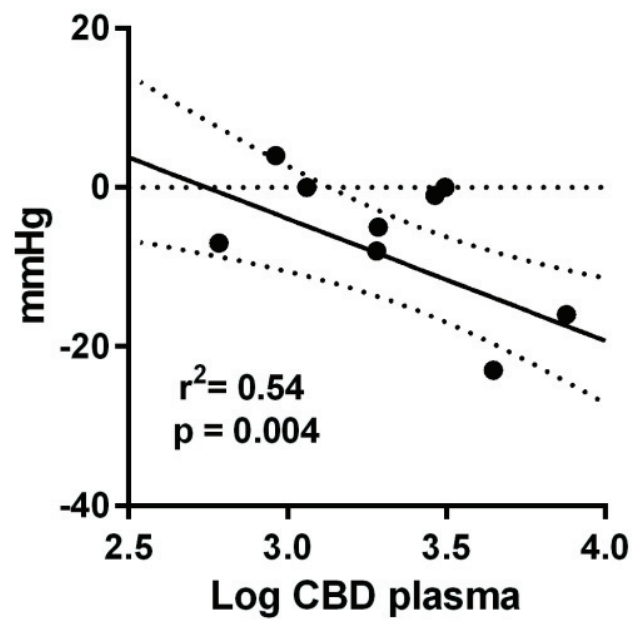

Fig 3: Blood pressure changes 2. Mean drop in MABP per group (a). Correlation of plasma

concentrations of CBD $3 \mathrm{~h}$ post-treatment with the degree of hypotension during infusion (b). Data presented as mean \pm SD. Statistics by One-way ANOVA with the Dunnets post-hoc test $* p<0.0001$. 